\title{
Daniela Karrenstein
}

\section{Der Menschenrechtsrat der Vereinten Nationen}

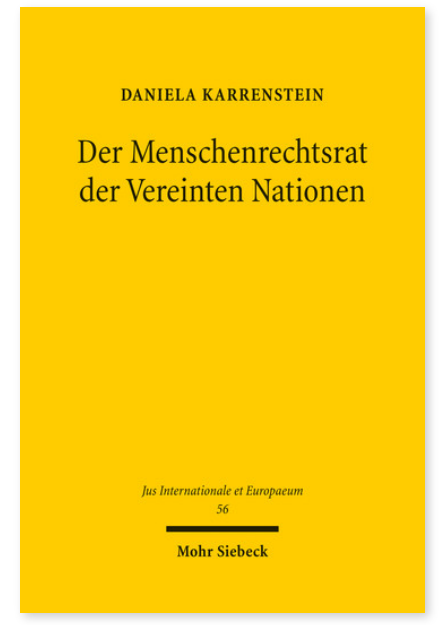

2011. XVIII, 313 Seiten. JusIntEu 56

ISBN 978-3-16-151755-6

DOI 10.1628/978-3-16-151755-6

eBook PDF 79,00€

ISBN 978-3-16-150909-4

fadengeheftete Broschur 79,00€
Mit der Umstrukturierung des zentralen Menschenrechtsschutzorgans der Vereinten Nationen, insbesondere mit dem neugeschaffenen Verfahren der Universal Periodic Review, verband sich einerseits die Hoffnung auf einen menschenrechtspolitischen Neuanfang. Andererseits galt es aber auch, die zahlreichen vorhandenen und vielfach in der Praxis bewährten Mechanismen, welche im Laufe der langen Geschichte der Menschenrechtskommission geschaffen worden waren, zu erhalten oder auszubauen und in das System des neuen Menschenrechtsrates zu integrieren. Gleichzeitig eröffnete sich die Chance, Dopplungen oder sonst ineffektive Strukturen zu beseitigen. Notwendig war deshalb - und ist teilweise bis heute - eine Bestandsaufnahme, Bewertung und Entscheidung über die Fortführung und Neuausgestaltung der vorhandenen Mechanismen. Diese von Daniela Karrenstein vorgenommene Bestandsaufnahme kann für die im Jahre 2011 vom Menschenrechtsrat durchzuführende Überprüfung seiner Funktionsweise nutzbar gemacht werden.

Daniela Karrenstein Geboren 1978; Studium der Rechtswissenschaft in Trier und Paris; 2011 Promotion; derzeit Beigeordnete Sachverständige im Sekretariat der Vereinten Nationen in New York.

\section{Jetzt bestellen:}

https://mohrsiebeck.com/buch/der-menschenrechtsrat-der-vereinten-nationen-9783161517556?no_cache=1 order@mohrsiebeck.com

Telefon: +49 (0)7071-923-17

Telefax: +49 (0)7071-51104 